\title{
Study on the Concepts of Residential Buildings under the Background of Green Building
}

\author{
Lei Chen
}

${ }^{1}$ University of South China, Hunan, 421001, China.

Keywords: Residential buildings, Green building, Concept

\begin{abstract}
This paper proposes the concepts of residential buildings under the background of green building. Based on the green building, symbiotic construction, energy-saving and ground-saving buildings and ecological construction and other types of practice and exploration, summing up the definition of the green building: step by step in the whole life cycle of the building. This paper is not only to discuss the diversity of the "starting point" in order to design the works, but also to understand the creative activity of the architectural design itself from a number of perspectives, so that it is profound in its sense, from the interpretation, On the rise, from the theory of the sublimation, from the evaluation of multi-standard, from the practice of multi-channel. In the future, the implementation of the method will be deploied.
\end{abstract}

\section{INTRODUCTION}

Green building is the name suggests that the green, healthy concept and the combination of a combination of the technical means, seemingly very simple question, it is not true, which also contains a lot of attention to our attention, discussion and the research. Based on the green building, symbiotic construction, energy-saving and ground-saving buildings and ecological construction and other types of practice and exploration, summing up the definition of the green building: step by step in the whole life cycle of the building, take up and consume the earth's resources to the greatest extent, dosage is the smallest and the most efficient use of energy, the least waste production and least harmful substances, environment and the natural harmonious coexistence as is advantageous to the ecosystem and human settlements system common security, health and meet the functional requirements, psychological needs, physiological needs and comfort requirements of sustainable building livable [1-3].

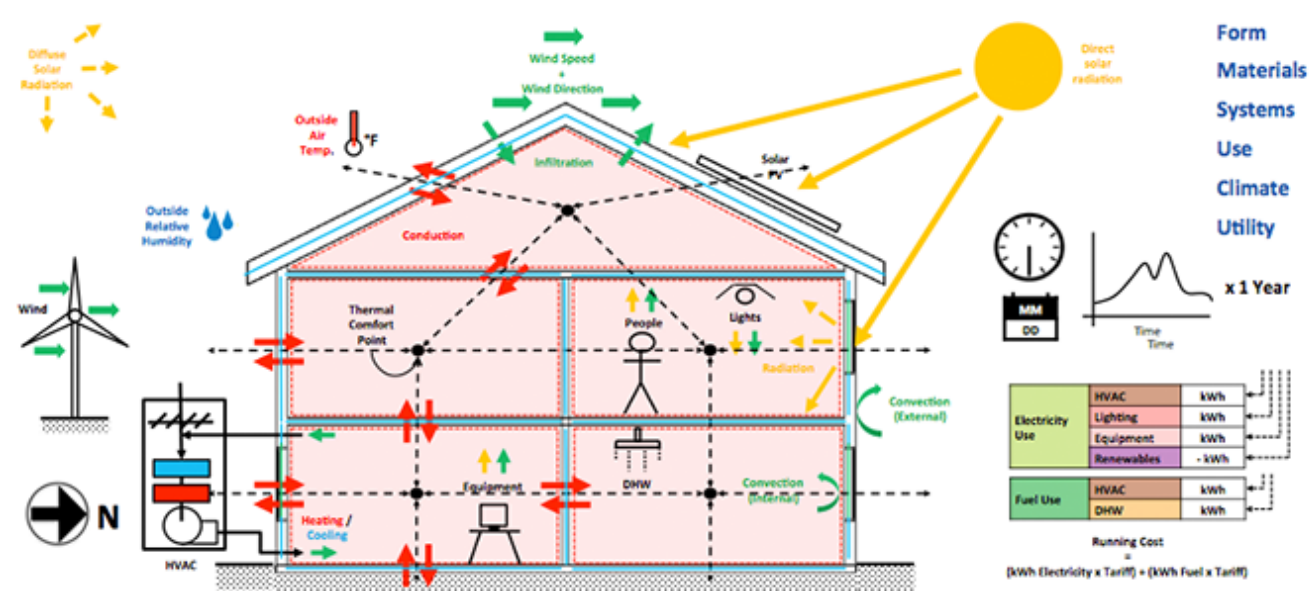

FIGURE 1. The Architecture of the Green Building

As shown in the figure one, architecture of the green building is demonstrated, green buildings are to consider how the climate characteristics, economic conditions, cultural traditions with each other to adapt to the surrounding environment as become inseparable part. The unique conditions of each project determine the building needs to be adapted to local conditions and combined with terrain and other related conditions to design. In the paper we will propose the concepts of residential buildings under the background of green building and the primary perspectives of the 
research will be focused on dealing with the listed issues.

- In the short-term rapid sales model, very few developers hold the property, which also caused a lot of the developers to low-cost, low-quality fast sales of product strategy to guide architectural design, the pursuit of their own interests to maximize the neglect of sustainable development.

- Under the mode of the one-sided pursuit of high speed development, some invisible infrastructure is not respected. Such as some urban rainwater discharge ability is insufficient, especially in big cities for the construction of subsided overpass, gathered the extent of the rainwater cannot estimate, leading to frequent floods under the heavy rain.

- Urban planning and architectural design of obsessed with image, formed a kind of important function of the city to focus on a type of planning of the fair.

\section{THE PROPOSED METHODOLOGY}

\section{Overview of the Architectural Design}

This paper is not only to discuss the diversity of the "starting point" in order to design the works, but also to understand the creative activity of the architectural design itself from a number of perspectives, so that it is profound in its sense, from the interpretation, On the rise, from the theory of the sublimation, from the evaluation of multi-standard, from the practice of multi-channel. In under the basic global initiative innovation macro environment, our country construction zone assumes the rise to the architectural design innovation attention and the research heat degree the tendency. But, the current our country architectural design innovation theory and the practice also has many problems, for example: 1) innovates the efficiency low, the process long as well as the stability is bad; 2) innovates the science and the rational insufficiency, the systematic characteristic not strong, randomness oversized, the intellectualized degree is not high; 3) innovates machinemade many excessively relies on inspiration flashing before, the uncertainty is big. At the same time, the current architectural design innovation faces the question and contradictory complicates day by day, depends on the perception and the experience purely carries on the innovation the mechanism increasingly to lack the ability to do what one would like.

Therefore, the task of the architectural design scientific, intelligent, rational has then become increasingly urgent. Extenics application in architectural design innovation, provide ideas, methods and tools for architectural design innovation, make the architectural design innovation process rationalization, effectively improve the efficiency of innovation with the combination of architecture and extenics with the innovation. Extension of architectural design innovation thinking is based on "extension of the thinking", the core is "extension analysis" and "transformation", its basic idea is: using the extension in the innovation thought and method, by adopting the combination of qualitative and quantitative way, explore the relationship between the design control factors, with the help of the logical, heuristic analysis and transformation, involved in the architectural design innovation, conditions, objects of target a methodical, specific, gradually realize the integration of design conditions, innovative solutions to the conditions in the architectural design problems, contradictions and value problems, and make the architectural design innovation in the past mainly rely on the inspiration, uncontrolled type black box process into relying more on the rational, the white box process can be controlled and increase the rationality, efficiency and stability of the innovation. And this core perspective can be analyzed from the following perspectives.

- The starting point of architectural design can have many choices as is also a "paper" design, can also use the space as the starting point of the design. According to the various constraints, prefab formed in a certain meaning space in the building, and the significance of space in the building should be in a core position, and other space around the central space, finally form the whole building.

- Theoretically, may think was the innumerable section planes combines the space, the splendid construction space was by certain has the quality section plane and gathers becomes. In this sense, the section plane has the qualifications compared to the plane to take the architectural design the 


\section{beginning.}

- When people are skillfully mastered the "paper design", while the design starting point may be difficult to distinguish between the plane space or profile. Because at the beginning of the design, to consider the flat, vertical, profile and space, at a certain height, the overall concept of the whole building. At this point, the plane, space or profile while who is the starting point that afraid it is difficult to have.

\section{Green Building}

The emergence of the green building marks the traditional architectural design from the only structure of the architectural aesthetics, space utilization, form, color, structure, color and other considerations, gradually to look at from the perspective of ecological architecture, which means that the building is not only to as nonliving elements, and more is seen as the an integral part of the ecological circulation system. Not only the green construction considered the local climate, the building shape, the use way, the facility condition, build the process, the building material, the use management to the basic external environment influence, as well as comfortable, health internal environment, simultaneously has considered the investor, the user, the design, the installment, the movement, and serviceman's stake. Then continues the design, the good environment and the profiting user three between should have the balance, the benign interaction relations, thus achieves optimized the whole afforestation effect.

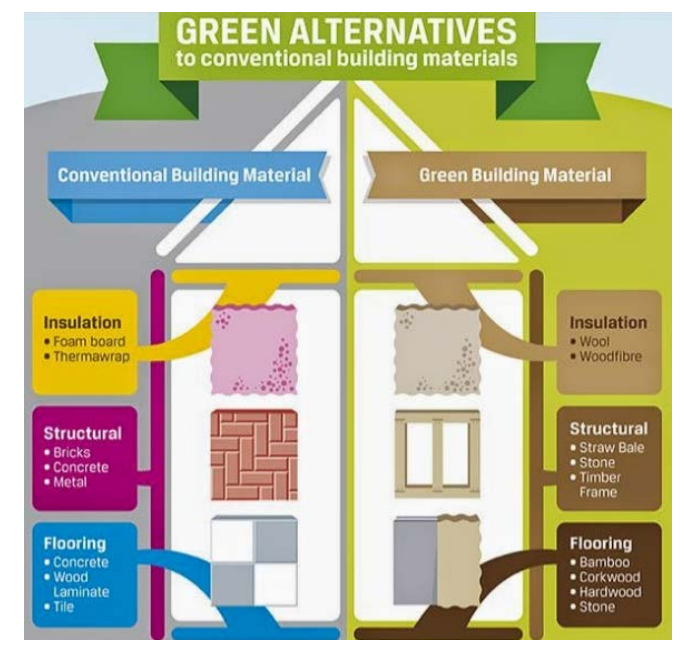

FIGURE 2. Green Building Architectures.

Green construction is the application of sustainable development in the construction of the application reflects the green construction technology is a comprehensive application. Green construction technology is not independent of the traditional construction technology of the new technology, but with the "sustainable" vision of the traditional construction technology to reexamine that is consistent with the sustainable development of the basic construction technology. The implementation of green construction should carry on the overall scheme optimization. In planning and design stage, we should give full consideration to the overall requirements of the green construction, to provide basic conditions for the green construction. The implementation of that green construction, construction planning, material purchasing, site construction, project acceptance and so on the various phases control strengthen the basic management of the whole construction process and overseers from the following aspects.

- In the aspect of renewable energy utilization, the key technologies of ground source heat pump and water source heat pump are researched, and the sea water source heat pump unit which can directly introduce seawater into the unit has been developed to improve the efficiency of the system and greatly reduce the cost of the system.

- In the new building materials aspect has researched and developed safely durable, the energy conservation environmental protection with the construction convenient green building materials. 
Developed the high strength rank cement, the high performance concrete, the high performance glass, the fire protection heat insulation performance good construction thermal insulation material, and the multi-purpose compound integrated wall material, the integrated roofing that broke the bridge heat insulation windows and doors, vacuum building materials and so on heat preservation board, visor system guided the high performance concrete, the high tensile steel to be supposed.

- In the field of the exquisite construction and the green construction technology and equipment, residential industrialization, industrialization began to take shape. Some achievements have been made in the field of material substitution with resource recycling, new technology, new tools and new construction technology.

\section{Residential Buildings}

Predominantly residential type "no architect of the building", it is an important part of building large family in China as is a unique architectural form. Its emergence and development is the social, economic, cultural and natural factors such as comprehensive reflection. Due to the geographical climate factors, local materials and the structure of the traditional technology and the methods is different, economic conditions, customs, ethics, etiquette, interest, thinking, experience and other factors and influence of the complex interaction between different regions, different nationalities of residence has its own unique artistic style and features. The environmental adaptability and some ecological representation of Chinese traditional houses are the reasonable adaptation modes formed in the long run of mankind and nature. That is, "through the choice of the best space and time to make people live in harmony with the earth and get the maximum benefit, to achieve peace and prosperity "of the ideal model. It can be said that they are the prototype and theoretical basis of contemporary ecological architecture. It is not difficult to find that the new thought theory of the contemporary ecological architecture of the West is exactly the same as the development of the traditional Chinese culture theory for thousands of years. It is also in line with the basic idea of "organic building" in the modern architecture movement. The ecologically-safe building is take the natural ecology principle as the basis, explores human, building, the nature three between relations that molds one for the humanity most comfortable reasonable also the sustainable development environment, as becomes the 21st century construction development the direction. But the Chinese tradition common people residence is the Chinese construction civilization important historical testimony, because it makes to the natural environment and the climatic conditions the unique explanation, and manifests China constructs and the nature harmonious thought, also becomes the construction zone attention once more the hot spot which will finally support the further development.

\section{CONCLUSION}

This paper proposes the concepts of residential buildings under the background of the green building. Along with social, the economical, the environment unceasing change and the development, the people ideology enhancement, with strengthens unceasingly to the environmental protection idea. The green construction will certainly to become the social construction mainstream in the future day, will complete the environmental protection is a very long path, in which also can face many challenges, we will certainly have diligently, to establish the human and the natural environment paragenesis altogether rest, ecology and economical common prosperity glorious future unceasingly. Green building is to implement "people-oriented", "a building-natural" harmonization and unification of the three necessary avenue is an important part of implementing sustainable development strategy in our country.

\section{REFERENCES}

[1] Zuo, Jian, and Zhen-Yu Zhao. "Green building research-current status and future agenda: A review." Renewable and Sustainable Energy Reviews 30 (2014): 271-281. 
[2] Meyer, M., et al. "Green school building success: innovation through a flat team approach." Constructing green: The social structures of sustainability (2013): 219-238.

[3] Schulz, Christian, and Bérénice Preller. "Keeping Up with the Pace of Green Building: Service Provision in a Highly Dynamic Sector." Services and the Green Economy. Palgrave Macmillan UK, 2016. 269-296.

[4] Liang, Ru-Ze, et al. "Optimizing top precision performance measure of content-based image retrieval by learning similarity function." arXiv preprint arXiv:1604.06620 (2016).

[5] Gong, Yunchao, et al. "Iterative quantization: A procrustean approach to learning binary codes for large-scale image retrieval." IEEE Transactions on Pattern Analysis and Machine Intelligence 35.12 (2013): 2916-2929.

[6] Zheng, Liang, et al. "Packing and padding: Coupled multi-index for accurate image retrieval." Proceedings of the IEEE Conference on Computer Vision and Pattern Recognition. 2014. 